\title{
El mito de Frankenstein en el cine: transmediación y ciencia ficción (Blade Runner y 2049)
}

\author{
The Frankenstein Myth in Film: \\ Transmediation and Science Fiction \\ (Blade Runner and 2049)
}

\author{
Pedro Javier Pardo \\ Universidad de Salamanca \\ pardo@usal.es \\ ORCID ID: 0000-0001-8347-5738
}

\begin{abstract}
Resumen: Este trabajo explora la presencia de Frankenstein en el cine a partir de un marco teórico basado en los conceptos de transtextualidad y transescritura. En su primera parte hace un recorrido por las transmediaciones que han convertido la novela en un mito, con un doble objetivo: en primer lugar, ilustrar el rendimiento del marco teórico y, en segundo lugar, alcanzar una definición del mito frankensteiniano, que se cifra en la dialéctica creador-criatura articulada por tres motivos narrativos y desarrollada en tres mitemas. En la segunda parte el artículo se interroga sobre la presencia de este paradigma en el cine de ciencia ficción $y$, primero, separa género de mito (lo que permite establecer grados de presencialidad), para luego ocuparse del grado máximo (donde el mito se hace sentir con su dialéctica característica), que se ilustra con el análisis detallado de Blade Runner y 2049.
\end{abstract}

Palabras clave: transescritura, transtextualidad, architexto, reescritura, transficción, posthumanidad, Frankenstein, Blade Runner, 2049.

\begin{abstract}
This essay explores the presence of Frankenstein in film through a theoretical frame based on the notions of transtextuality and transwriting. The first part is a survey of the series of transmediations which have turned the novel into a myth and entails a double aim: in the first place, to illustrate the efficiency of the theoretical frame and, in the second place, to reach a definition of the Frankensteinian myth, which is anchored in the dialectics between creator and creature, articulated by three narrative motifs and expressed in three mythemes. The second part probes the presence of this paradigm in science fiction and, firstly, it distinguishes between myth and genre (which leaves room for different degrees in this presence), so then it focuses on the highest degree (where the dialectics of myth can be detected), which is illustrated by a detailed analysis of Blade Runner and 2049.
\end{abstract}

Key Words: transwriting, transtextuality, architext, rewriting, transfiction, posthumanity, Frankenstein, Blade Runner, 2049. 


\section{INTRODUCCIÓN: TRANSTEXTUALIDAD Y TRANSESCRITURA}

What is a Frankenstein film? Esta es la pregunta que plantea Shane Denson en la introducción (2014: 27) de la penúltima monografía sobre la progenie fílmica de la novela de Mary Shelley, Frankenstein, or The Modern Prometheus (1818). Por un lado, este autor admite que no podemos limitarnos a incluir en esta categoría las adaptaciones de la novela de Shelley, pues ya las primeras películas de la Universal que la llevaron al cine fueron mucho más allá de la novela e iniciaron una tradición de lo que Denson denomina derivaciones y desviaciones de la narrativa fundacional. Pero, por otro lado, reconoce que incluir en esta categoría todas las películas que llevan en el título la palabra Frankenstein, empezando por las famosas series de películas no solo de la Universal sino también de la Hammer, nos deja sin «a particular set of narrative events; at most, there is a shared focus on acts of creation and the consequences of such acts, along with a very general thematic exploration of human-technology relations and attendant socio-cultural conflicts» (2014: 30). Si, además, ampliamos el Frankensteinian cinemyth (Picart, 2003: 1) a títulos de ciencia ficción como The Thing, las sagas Alien y Terminator, o Blade Runner, estamos ante lo que Denson denomina inflationary approach (2014: 31), pues, en su opinión, expande en exceso el concepto de filme de Frankenstein y lo hace inoperativo, por ocultar o al menos relegar en exceso su historicidad ${ }^{1}$. Por ello, descarta esta categoría de mito cinematográfico para el corpus que es su objeto de estudio y sugiere una vía intermedia que lo considera algo parecido a un género (quasi-generic formation) por su dinámica de repetición y variación (2014: 34). Desde nuestro punto de vista, la vía intermedia no pasa tanto por unificar el concepto de Frankenstein film en una sola categoría (sea esta la de adaptación concebida en términos de fidelidad, de género para dar cabida a la desviación, o de mito que permite un parentesco más lejano), excluyendo por tanto aquellos filmes que no encajan en ella; sino por identificar los diferentes modos en que el potencial corpus cinematográfico frankensteiniano puede relacionarse con el modelo literario.

Para ello, y como ya apunté en un artículo (2005) que el propio Denson comenta en su libro como representativo del enfoque mítico (2014: 32), es fundamental distinguir claramente la novela del mito generado a partir de ella y ser conscientes de que muchas - por no decir la

\footnotetext{
${ }^{1}$ Caroline Picart cifra este mito fílmico en el nacimiento por partenogénesis y la representación de lo femenino como monstruoso: «Two elements bind my previous work to this project: (1) the emphasis on parthenogenetic births (male self-births, such as Frankenstein's birthing of his creature), and (2) the focus on the third shadow, the representation of the female monster and the feminine-as-monstruous, as a crucial site of ambivalence revelatory of tensions regarding gender, power, and technology» (2003: 2). Para este enfoque que incluye en el mito películas de ciencia ficción, véase también, entre otros, Frentz y Hocker (1994), Clayton (2003) o Pardo (2008).
} 
mayoría- de las películas, han tomado este más que aquella como su punto de referencia. Por ello, hay que estudiar, en primer lugar, el trasvase de la novela a otros medios (no solo el cine sino, como veremos, también el teatro), aunque sin limitarlo a la reproducción y dando cabida a la expansión y la transformación, es decir, contemplando las tres operaciones que he denominado imitación, transficción y reescritura y he estudiado bajo la rúbrica de transescritura, esto es, la transferencia o migración de universos diegéticos entre obras, en un trabajo anterior (2018). Y hay que reconocer, en segundo lugar, que este proceso de transescritura ha dado lugar a un mito, es decir, un patrón narrativo recurrente que puede identificarse en productos cuya relación con la novela es ya muy tenue o incluso inexistente. La situación es aún más compleja porque, para muchos, la novela de Mary Shelley es un texto fundacional del género de la ciencia ficción, que no se caracteriza tanto por un patrón narrativo recurrente que pudiera considerarse o confundirse con un mito, sino por una serie de problemas o temas y, sobre todo, por una manera de plantearlos, como veremos más adelante. Ello nos ofrece tres vías de acceso a la fortuna cinematográfica de Frankenstein -la novela, el género y el mito- que pueden enriquecerse aún más si atendemos a la tipología genettiana de la transtextualidad (1982) e incorporamos sus conceptos de intertextualidad, hipertextualidad y architextualidad. El primero designa la referencia específica y microtextual (cita, alusión, préstamo); el segundo el modelo macrotextual (hipotexto) sobre el que se construye otro texto (hipertexto); el tercero la relación de un texto con paradigmas generales o architextos (formas, motivos, géneros, mitos), es decir, con cualquier tipo de patrón narrativo, configuración formal o agrupamiento temático que se hace presente en él.

La adaptación cinematográfica de textos literarios es, evidentemente, una forma de hipertextualidad que incluye las operaciones de transescritura que hemos enumerado arriba. En otras palabras, la transmediación, es decir, la transferencia de una obra desde un medio a otro, no tiene por qué limitarse a la reproducción de sus contenidos, sino que puede intervenir sobre ellos transformándolos o expandiéndolos, lo que amplía considerablemente el arco de las adaptaciones fílmicas de Frankenstein. Pero ello no agota su transmedialidad, es decir, la copresencia de varios medios en una obra, ya que esta incluye también otras variantes de la transtextualidad genettiana; de forma que una película puede utilizar la novela de Mary Shelley no solo como hipotexto (modelo global), sino también como intertexto (referencias puntuales) o como architexto, y en este último caso puede hacerlo como paradigma genérico (ciencia ficción) o narrativo (mito). Además, tales posibilidades pueden darse de manera aislada o en combinación, de forma que, por ejemplo, una película basada en el hipotexto literario puede desplazarlo architextualmente a otros géneros fílmicos diferentes del terror o la ciencia ficción; filmes que utilizan no tanto el hipotexto literario como el architexto fílmico generado 


\section{Pedro Javier Pardo}

a partir de él pueden incluir alusiones intertextuales a la novela; y la architextualidad puede detectarse simultáneamente en la traza del argumento mítico y en el sustrato genérico común. La intersección de todas estas categorías teóricas, por tanto, nos da un instrumental no solo terminológico sino metodológico muy valioso para abordar la posteridad fílmica de Frankenstein, de la que nos ocuparemos en la primera parte de este trabajo. Además, nos permite acometer con rigor lo que será su segunda parte, a saber, la espinosa cuestión de la indudable relación que algunas películas de ciencia ficción mantienen con la obra de Shelley más allá de su parentesco genérico.

\section{DEL LIBRO AL MITO: FRANKENSTEIN TRANSMEDIAL}

\subsection{Del teatro al cine}

La transformación de Frankenstein en un mito se debe al teatro antes que al cine: el séptimo arte vendrá a desarrollar en el siglo XX y en la pantalla el proceso que ya se había empezado a producir sobre los escenarios decimonónicos, como demuestra el hecho de que el referente inicial de las primeras transmediaciones fílmicas no será la novela de Shelley sino alguna de sus dramatizaciones.

En este sentido, el proceso de mitificación está ligado desde el principio a la transmediación, pues surge del impulso de adaptar el texto literario a un modo de presentación mimético en vez de diegético. Hoeveler (2016: 175-76) explica perfectamente cómo la popularidad de la novela (en 1831 aparece ya una tercera edición revisada) no se debió al éxito de la misma, cuyas ventas en su primera edición de 1818 fueron escasas, sino al de la adaptación teatral que se estrenó pocos años después, en 1823, a una de cuyas representaciones en la English Opera House (puesto que, aunque suele olvidarse, era un musical que incluía canciones) asistió la propia Shelley en compañía de su padre William Godwin el 29 de agosto (Schor, 2003: 63). Tal adaptación era la obra de Richard Brinsley Peake Presumption; or The Fate of Frankenstein, que se representó 37 veces en la temporada de su estreno, lo que provocó la aparición de otras adaptaciones ya ese mismo año, como informa Hoeveler ${ }^{2}$. Y el teatro

\footnotetext{
${ }^{2}$ « [...] another melodrama which has been lost -Henry M. Milner's Frankenstein; or, The Demon of Switzerland (Royal Coburg Theatre, 18 August 1823-an early version of his later The Man and the Monster; Peake's adaptation of his own earlier adaptation, Another Piece of Presumption (Adelphi Theatre, 20 October 1823); and three very light burlesques. It was because of the success of these various theatrical adaptations that a second edition of the novel was commissioned and published in 1823 by Whittaker. And, as William St Clair has noted, "every single night when one of the Frankenstein plays was performed brought a version of the story of the manmade monster to more men and women than the book did in ten or twenty years"» (2016: 176). Más adelante añade: «The popularity of the Peake adaptation can be seen in the fact that performances in Great Britain continued throughout the $1820 \mathrm{~s}$
} 
seguirá siendo el medio principal de popularización y difusión de la obra a lo largo del siglo XIX, de forma que a esta primera dramatización seguirán la de Henry M. Milner, The Man and the Monster; or, The Fate of Frankenstein (1826), y la de John Kerr, The Monster and the Magician; or, The Fate of Frankenstein (1826), que, curiosamente, es la traducción inglesa de la versión francesa de la obra de Peake (Le monstre et le magicien, 1826). Más tarde llegarán la de William and Robert Brough Frankenstein; or, The Model Man (1849), una interesante politización del mito, y la de Richard Henry (pseudónimo de Richard Butler y Henry Chance Newton) Frankenstein; or, The Vampire's Victim (1887). Aunque al poco aparece el cine para convertirse en el hábitat natural de Victor y su criatura, ello no ha sido incompatible con la continuidad de las dramatizaciones en el siglo XX, como ha puesto de manifiesto Lavalley (1979), quien menciona la de Peggy Webling (escrita en 1927), la del Living Theatre en 1966 y el musical The Rocky Horror Show (Richard O’Brien y Jim Sharman, 1973), y que llega hasta nuestros días. La última es la de Nick Dear, estrenada en el National Theatre en 2011 y, por fortuna, grabada para su difusión en salas de cine. Ello es muy revelador de cómo, si bien es cierto que el medio fílmico no ha extinguido las adaptaciones teatrales, su dominio las ha condicionado, como prueba no solo que el acceso mayoritario a esta última haya sido como grabación audiovisual (quien esto escribe pudo verla en un cine de Salamanca en 2018), sino que su director fuera el cineasta Danny Boyle, algo que se deja notar en la puesta en escena.

Esta doble cinematización del Frankenstein del National Theatre es un buen testimonio de cómo el advenimiento del cine en el siglo XX ha desplazado al teatro a los márgenes del proceso de transmediación. El cine mudo ya se ocupa tempranamente de la obra de Mary Shelley en tres adaptaciones $^{3}$, pero la entrada en el medio fílmico por la puerta grande se produce con el sonoro y las dos películas de James Whale para la Universal, Frankenstein (1931) y The Bride of Frankenstein (1935), cuyas notables divergencias de la novela se explican en parte por su inspiración en la tradición teatral. La primera, en efecto, se basa en la adaptación de Webling, a su vez adaptada para el público norteamericano por John L. Balderstone, y en ella se privaba del lenguaje a la criatura, como ya había ocurrido en la primera adaptación de Peake; la segunda se lo devolvía con la propina de un nombre (el del creador, origen de una confusión que se ha hecho endémica), como apunta Tropp (1999: 77); y aparecía la figura del ayudante de Frankenstein que había incorporado también Peake y que se convertirá en una constante. Los hipertextos teatrales se convierten así

and 1830s. The first American performance was staged in 1825, and the French version, Le monstre et la magicien, opened in Paris in 1826» (Hoeveler, 2016: 179).

3 Además del Frankenstein de la Edison (J. Searle Dawley, 1910), hay dos filmes mudos perdidos, Life Without Soul (Joseph W. Smiley, 1915) e Il monstro di Frankenstein (Eugenio Testa, 1920). 
en hipotexto del primer hipertexto cinemático sonoro, o al menos este tiene un hipotexto múltiple (el teatral y el novelesco), lo que explica la lógica transformacional que hace del filme una reescritura en vez de una imitación. La proliferación de secuelas transficcionales de esta primera película introduce una lógica expansiva hasta crear un ciclo (siete filmes entre 1931 y 1945) en el que la criatura acabará desplazando al creador como protagonista ${ }^{4}$. La dinámica de variación y repetición que introduce la serialidad desarrolla el proceso de mitificación que había iniciado el teatro y que se prolonga con una nueva serie, la de la productora británica Hammer, que se extiende de 1957 a 1974 a lo largo de otras siete películas. En ellas se rehistoriza el mito, aunque en la época victoriana, el creador -ahora más Decadente que Romántico- tendrá primacía sobre la criatura y el color se pondrá al servicio de un erotismo evidente y de unos decorados más llamativos ${ }^{5}$. Después de la Hammer el paradigma mítico continúa su desarrollo fílmico en un largo recorrido que puede seguirse en las visiones de conjunto de Tropp (1999), Jancovich (2016), y Friedman y Kavey (2016). Nos limitaremos a apuntar aquí los hitos fundamentales de este que podemos denominar el Frankenstein transmedial, con el propósito de ilustrar las diferentes modalidades de transescritura y transtextualidad que hemos apuntado más arriba, y como paso previo a la descripción del paradigma architextual.

\subsection{Del siglo $\mathrm{XX}$ al $\mathrm{XXI}$}

Coincidiendo con el final del ciclo de la Hammer aparecen un grupo de películas que tienen en común el afán de modernizar y renovar un mito cuyos exponentes fílmicos han quedado obsoletos, un proceso que Lavalley explica como fruto de la autoconciencia dada por la larga práctica instaurada por la Universal y la Hammer (1979: 278). Sin duda estos filmes pueden reinterpretar el mito de manera más personal y creativa porque este ya está firmemente establecido en el imaginario colectivo, y lo hacen siguiendo una serie de prácticas transescriturales que serán recurrentes a partir de ese momento.

\footnotetext{
${ }^{4}$ Dejamos fuera Abbott and Costello Meet Frankenstein (1948), que no pertenece propiamente a este ciclo sino a un ciclo diferente en el que estos famosos cómicos se van encontrando con todas las criaturas de las películas de terror de la Universal, en esta primera con Frankenstein, el hombre lobo y Drácula. Hay otra película que continúa la dinámica expansiva creada por la Universal llevándola al siglo XX, Frankenstein 1970 (Howard W. Koch, 1958), como revela el hecho de que en ella interviene Boris Karloff, aunque interpretando ahora al creador, un descendiente de Victor Frankenstein, en vez de la criatura (como hacía en el ciclo de la Universal).

${ }^{5}$ Su huella es evidente en una curiosa producción italiana, La figlia de Frankenstein, conocida internacionalmente como Lady Frankenstein (Mel Welles y Aureliano Lupi, 1971), en la que Joseph Cotten interpreta al barón Frankenstein y Rosalba Neri a su hija.
} 
(1) En primer lugar, podemos detectar el tipo de reescritura heterodiegética transnacional (es decir, desarrollada en un universo diegético diferente al del hipotexto, en este caso otro país) observable en Flesh for Frankenstein (Paul Morrissey, 1973, conocida en Norteamérica como Andy Warhol's Frankenstein), cuya truculencia y morbosidad, tanto en lo referente al sexo como a las vísceras, apunta a los filmes de la Hammer, llevando el comportamiento aberrante que define a su creador a tal extremo que bordea la parodia. Lo más interesante, sin embargo, es el giro político que se le da al mito: el barón Frankenstein es un noble serbio de ideas clasistas y supremacistas que crea tanto un hombre como una mujer con la aspiración de que su copulación dé lugar a una raza superior que solo lo obedezca a él. Además de esa voluntad de führer, sus concomitancias con el proyecto nazi se explicitan en el aspecto ario de las criaturas (con la extrema importancia que le da a la nariz) y la música de Wagner que acompaña la creación. El final sugiere que son los vástagos naturales del barón, que han aprendido como voyeurs las aberraciones científicas y sexuales de sus padres, los llamados a consumar el proyecto racial y los herederos de la monstruosidad paterna.

(2) Si esta película mira a la Hammer, Young Frankenstein (Mel Brooks, 1974) se inspira en la Universal, que parodia abiertamente (como se observa ya en la misma fotografía en blanco y negro o la presencia de una serie de escenas clave: la creación, el encuentro con la niña o con el ermitaño ciego) y convierte en comedia, dando lugar a una transgenerización. Su carácter heterodiegético viene aquí dado por la trasferencia temporal en vez de espacial: se trata de una actualización que lleva el universo diegético original a un contexto contemporáneo. Ello explica la interpretación psicoanalítica que puede vislumbrarse e incide en la dualidad: el nieto de Victor Frankenstein, profesor en una universidad norteamericana, puede superar la escisión interna que supone la autorrepresión de sus raíces familiares (por ello pronuncia su apellido Fronk-en-steen) y la represión sexual a que lo somete su prometida, gracias a su criatura, a la que transfiere parte de su inteligencia y de la que obtiene un aumento de virilidad, quedando así unidos por una cierta especularidad invertida. Parecidas actualizaciones y transgenerizaciones del mito abundan en productos más abiertamente comerciales o incluso de ínfima categoría a partir de los 70, empezando por la inclasificable Frankenstein on Campus (Gilbert W. Taylor, 1970), el curioso cruce -crossover en inglés, muy cultivado en el ciclo de la Universal- Dracula vs Frankenstein (Al Adamson, Samuel M. Sherman, 1971), o el blaxploitation Blackenstein (también distribuida como Black Frankenstein, William. A. Levey, 1973); y siguiendo con otras cintas en los 80 y 90, casi todas 
herederas de la sexualización del mito observable en todos estos filmes de $\operatorname{los} 70^{6}$.

(3) Además, una película de la misma época que abunda en esta reinterpretación sexual y convierte el musical teatral que transmedializa en objeto de culto, The Rocky Horror Picture Show (Jim Sharman, 1975), representa lo que podemos denominar el desplazamiento, que es una forma de reescritura heterodiegética similar a la actualización en la que simplemente falta la identificación explícita del mito, aunque puede incluir alusiones más o menos sutiles. A la transgresión frankensteiniana se añade aquí la transexualidad, que abarca desde el travestismo que domina el vestuario del creador y la estética del filme hasta su promiscua y subversiva bisexualidad. El hecho de que Frankenfurter es un «transexual transvestite from Transylvania» y de que Transilvania es un planeta al que retorna el castillo entero con sus moradores al final, acerca el filme de forma lúdica a la ciencia ficción. En esta línea podemos también englobar otras tres películas: Making Mr. Right (Susan Seidelman, 1987), que prescinde por completo de alusiones al mito para explotar esa misma veta de la comedia de ciencia ficción con un propósito supuestamente feminista; Edward Scissorhands (Tim Burton, 1990), que convierte el mito en un cuento de hadas ambientado en un barrio residencial norteamericano yuxtapuesto de manera imposible con un castillo y un creador que proclaman sus orígenes góticos; y May (Lucky McKee, 2002), un relato de inadaptación juvenil y búsqueda de identidad sexual en el que el mito está tan desplazado (hay

\footnotetext{
${ }^{6}$ I was a Teenage Frankenstein (Herbert L. Strock, 1957) y Frankenstein Meets the Space Man (Robert Gaffney, 1965) son las precursoras de esta veta popular claramente reconocible porque el Frankenstein del título se refiere a la criatura. Todas ellas transforman a la criatura ahora identificada con el nombre del creador en un género de persona o de película de carácter marcadamente contemporáneo, a veces en otro contexto nacional: tras llevarlo a la adolescencia, a enfrentarse con extraterrestres, a la universidad y a la raza negra, la criatura será prostituta en la paródica Frankenhooker (Frank Henenlotter, 1990) y lesbiana en una película a medio camino entre el fantástico y el porno, Lust for Frankenstein (Jesús Franco, 1998, Lady Frankenstein es España), en el que se inscriben abiertamente Mistress Frankenstein (Fred Bacchus, 2000) y Bikini Frankenstein (Fred Olen Ray, 2010); se trasplanta en Italia con un carácter marcadamente erótico en Frankenstein '80 (Mario Mancini, 1972) o en Francia con uno abiertamente cómico en Frankenstein 90 (Alain Jessua, 1984); incluso será estrella musical hecha de partes de conocidos rockeros en Rock 'n' Roll Frankenstein (Brian O'Hara, 1999). Pueden encontrarse más transgenerizaciones cómicas en Frankenstein: The College Years (Tom Shadyac, 1991), Frankenstein and $\mathrm{Me}$ (Robert Tinnell, 1996) y Billy Frankenstein (Fred Olen Ray, 1998). Hay otro cruce actualizador en la europea Los monstruos del terror (Tulio Demichelli, 1970) y, ya sin actualización, en la cinta de Jesús Franco Drácula contra Frankenstein (1972), al igual que en la delirante transgenerización que lleva la criatura al oeste americano Jesse James Meets Frankenstein's Daughter (William Beaudine, 1966) o a competir en potencia sexual con Drácula en House of Bare Mountain (1962).
} 
una única alusión en el tatuaje de Boris Karloff como la criatura que un personaje secundario exhibe en el hombro) que no aparece en ningún repertorio de filmes frankensteinianos. A ellas se puede añadir el quinto episodio de la sexta temporada de The X-Files, significativamente titulado The Post-modern Prometheus (1997), un claro homenaje a los filmes de la Universal (el episodio está rodado en blanco y negro) y su construcción social de la monstruosidad que nos recuerda que en nuestro recorrido por el Frankenstein transmedial debemos también mirar a la televisión.

(4) En efecto, todas estas películas se inspiran en el architexto más que en el texto fundador, pero, si acudimos a la pequeña pantalla, podemos detectar también en los 70 un retorno al hipotexto literario para construir un hipertexto que se presenta como restauración cinematográfica de la novela original, como se observa ya en el subtítulo del telefilme que inicia esta tendencia: Frankenstein: The True Story (Jack Smight, 1973, con la participación de Christopher Isherwood en el guion). La realidad, sin embargo, es que, en vez de una imitación, se trata de una reescritura homodiegética, pues transforma el universo diegético de la novela de Mary Shelley sirviéndose de elementos tomados de la tradición cinemática previa (incluido un interesante subtexto sexual en línea con lo que parece ser la reinterpretación dominante en los 70 , que aquí se orienta hacia la temática homosexual: al final la historia verdadera resulta ser no la que contó Mary Shelley, sino la que no contó). Sí es real el retorno a la novela en otros telefilmes que se anunciaron con fundamento como «the true dramatisation of Mary Shelley's classic novel» (James Ormerod, 1984) o the real story (David Wickes, 1992). Y, de manera más engañosa, la estrategia reaparece en la adaptación cinematográfica posiblemente de referencia: Mary Shelley's Frankenstein (Kenneth Branagh, 1994). El título llama la atención sobre la presencia de la novela como hipotexto, pero las diferencias son muy llamativas, sobre todo en lo referente a la criatura femenina y la temática de género ${ }^{7}$.

(5) Finalmente, la posibilidad de que Frankenstein se haga presente como intertexto se actualiza en otro filme de los años 70, El espíritu de la colmena (Víctor Erice, 1974), donde se cita la primera película de Whale mediante su proyección en un pueblo de la España de posguerra y sirve

\footnotetext{
${ }^{7}$ En ello es también heredera, además de Frankenstein: The True Story, de otra película más cercana y centrada en Eva, la criatura femenina: The Bride (Franc Roddam, 1985), que comparte el carácter homodiegético aunque vagamente victoriano (lo que muestra cómo lo que hemos llamado feminización del mito no se limita a las reescrituras heterodiegéticas), si bien el nombre del creador (Charles Frankenstein) marca distancias tanto con el texto literario (Victor) como con los hipertextos fílmicos (Henry en el ciclo de la Universal, con cuya The Bride of Frankenstein puede relacionarse), situándose así en una posición abiertamente architextual.
} 


\section{Pedro Javier Pardo}

para explicar así su presencia en la imaginación de una niña. Algo similar, pero ahora con la novela, ocurre en Remando al viento (Gonzalo Suárez, 1988), que narra la gestación y escritura de la obra por parte de Mary Shelley y cómo la criatura salta del libro a la realidad para perseguir a su creadora y su círculo. En ambos casos, la presencia intertextual de novela o filme en el nivel metadiegético apunta a la presencia del architexto frankensteiniano en el intradiegético, y caracteriza ambas obras como el tipo de expansión transficcional que Saint-Gelais, en su exhaustivo estudio de esta categoría (2011), ha denominado captura. Otro ejemplo de este tipo de transficción es Frankenstein Unboud (Roger Corman, 1990), basada en la novela de Brian Aldiss del mismo título.

En los años 70 se produce así una renovación en el tratamiento cinemático del mito cuyas líneas maestras se extienden no solo a las décadas finales del siglo XX, sino también a las iniciales del siglo XXI, aunque este también traerá innovaciones propias: un nuevo énfasis en la expansión transficcional y en la reconstrucción histórica neovictoriana, así como la irrupción de la serialidad televisiva que también expande, aunque en otro sentido. De hecho, lo que podríamos llamar el Frankenstein catódico del nuevo siglo ofrece un perfecto compendio tanto de los tres tipos de transescritura transmedial que hemos establecido más arriba como de la sustitución del texto por el architexto:

(1) La imitación es evidente en la que es tal vez la ilustración audiovisual más fiel de la novela (como revela la presencia inicial de Walton como receptor del relato oral de Victor), el Frankenstein norteamericano de Kevin Connor (2004).

(2) El británico de Jed Mercurio (2007) es una reescritura concebida como actualización heterodiegética de naturaleza architextual (como revelan los evidentes ecos intertextuales con el ciclo de la Universal), que además completa el proceso de feminización comentado más arriba, pues en vez de añadir una criatura femenina o mujeres empáticas como compañeras del doctor o de la criatura, presenta a una doctora Victoria Frankenstein que accidentalmente resucita a su hijo como criatura.

(3) Esta naturaleza architextual es aún más manifiesta en el Frankenstein de Marcus Nispel (2004), pues se trata de una transficción basada en la captura (con unos Victor Helios y Deucalion inmortales, los supuestos modelos en que se inspiró Shelley, moviéndose por una Nueva Orleans contemporánea), además de una transgenerización hacia el relato policial, con una criatura que posee capacidades que lo aproximan al superhéroe.

La transficción expansiva se hace también evidente en el cine, donde el mito se diluye y es apenas reconocible. Así ocurre cuando penetra en el 
territorio genérico del cine de superhéroes retrofuturista y distópico, con claros ecos de la saga Underworld, en I, Frankenstein (Stuart Beattie, 2014). Reencontramos a la criatura inmortal, pero ahora de vuelta en el género de terror, como un monstruo salvaje en vez de superhéroe en The Frankenstein Theory (Andrew Weiner, 2013), que hace un muy interesante uso de la captura. Dos expansiones curiosamente similares ya desde el título, Frankenstein's Army (Richard Raaphorst, 2013) y Army of Frankensteins (Ryan Bellgardt, 2014), ponen el mito en un contexto bélico pasado, la Segunda Guerra Mundial y la Guerra de Secesión norteamericana, respectivamente, en el que la fabricación seriada de criaturas por un científico fuera de control (identificado como un descendiente de Frankenstein en la primera) amenaza con cambiar el curso de la historia ${ }^{8}$. El cine del siglo XXI también ha practicado la reescritura tanto heterodiegética como homodiegética, aunque con el dominio de la primera en su variante actualizadora. Aquí hay tres filmes de mucho interés que reinterpretan el mito en diferentes direcciones: (1) Frankenweenie (Tim Burton, 2012), parodia en blanco y negro los filmes de James Whale en la Universal llevándolos a un territorio genérico sorprendente, el cine de animación de temática infantil (lo que no quiere decir que sea para niños); (2) Frankenstein (Bernard Rose, 2015) actualiza el mito, potencia la marginalización e introduce a una compañera del creador que juega un rol maternal con la criatura; (3) Depraved (Larry Fessenden, 2019) hace lo mismo, ahora con el trasfondo de la relación paterno-filial entre creador y criatura y de la guerra de Irak cuyas consecuencias traumáticas desencadenan la empresa creadora. Además, Victor Frankenstein (Paul McGuigan, 2015) lleva la reescritura homodiegética a ese territorio en que empieza a deja de serlo, la reconstrucción histórica del mito en la época victoriana. El referente no es el texto sino el architexto, como pone de manifiesto la presencia como

\footnotetext{
${ }^{8}$ Un antecedente de estas expansiones por la importancia que cobra la dimensión fantástica, monstruosa e incluso futurista que desdibuja o diluye el mito y roza el despropósito, es la película japonesa Frankenstein Conquers the World (Ishiro Honda, 1965), también conocida como Frankenstein vs. Baragon (siendo este un sucedáneo de la conocida Godzilla). También debemos incluir aquí la ya citada Frankenstein 1970, protagonizada por un descendiente del doctor Frankenstein, como ocurre con un tercer antecedente, Frankenstein's Daughter (Richard E. Cunha, 1958). Hay expansiones posteriores con el mismo énfasis en el científico emparentado con su eminente ancestro y en las aberraciones de la ciencia y los científicos fuera de control, como Frankenstein's Island (Jerry Warren, 1981), con un planteamiento que evoca el clásico de H. G. Wells The Island of Doctor Moreau (1896); y, repitiendo el motivo de la isla, pero ya en el siglo XXI, Frankenstein Reborn (Leigh Scott, 2005). Además, sin parentesco con el doctor Frankenstein, pero en esta misma línea muy cercana a la ciencia ficción o la fantasía con base científica, hay tres actualizaciones: Frankenstein vs. the Creature from Blood Cove (William Winckler, 2005), The Frankenstein Syndrome (originalmente The Prometheus Project, Sean Tretta, 2010) y Frankenstein vs. The Mummy (Damien Lee, 2015).
} 
coprotagonista del ayudante Igor, quien encuentra refugio para su marginalidad en el circo (al igual que la criatura en The Bride), en la tradición de Freaks (Tod Browning, 1932).

Naturalmente, tal reconstrucción está concebida desde la sensibilidad (pos)moderna, por lo que forma parte de la corriente que se ha dado en llamar Neovictorianismo, y este Frankenstein neovictoriano ha dado sus mejores frutos en la pequeña pantalla. Penny Dreadful (John Logan, 20142016, 3 temporadas) desarrolla las posibilidades de un cruce de personajes literarios decimonónicos tomados de diferentes obras a los que se hace coincidir al final de la época victoriana ${ }^{9}$. En la línea de acción del doctor Frankenstein tomará protagonismo primero una criatura masculina, Caliban, con clara conciencia de su marginalidad, que reivindica citando de memoria a los poetas Románticos, y luego una femenina, Lily, que es la new woman victoriana pasada por el tamiz del feminismo radical. En The Frankenstein Chronicles (Benjamin Ross y Barry Langford, 2015-2017, 2 temporadas), un detective neovictoriano, es decir, atormentado por los males del sujeto (pos)moderno, investiga las muertes que lo conducirán a la realidad en la que supuestamente se inspiró Mary Shelley para escribir su novela; la autora aparece como un personaje más de la serie, lo que identifica a esta como una transficción basada en la captura. En ambos casos estamos ante una nueva serialidad televisiva que no se limita a producir episodios autónomos en torno a uno o varios protagonistas, sino ciclos que permiten desarrollar su universo diegético con una extensión y a veces profundidad similar lo que permite una novela, y que se ha convertido así en un factor de revitalización del mito característico del siglo XXI. Ello se ve confirmado por el hecho de que la imitación televisiva de Kevin Connor, si bien comercializada en DVD como como una película de aproximadamente tres horas, fue originalmente emitida como una miniserie de 204 minutos repartidos en 2 episodios; o que el Frankenstein de Marcus Nispel, producido nada menos que por Martin Scorsese, era el episodio piloto de lo que aspiraba a ser una serie. De hecho, su guionista, Dean Koontz, trasladaría no solo la trama de la película sino esta voluntad de serialidad a un ciclo de cinco novelas conocidas como Dean Koontz's Frankenstein, cuya primera entrega, Prodigal Son (2005), apareció justo al año siguiente del filme. Los libros de Koontz, naturalmente, nos recuerdan que la literatura también ha sido territorio abonado para

\footnotetext{
${ }^{9} \mathrm{El}$ antecesor de este cruce neovictoriano en la gran pantalla es Van Helsing (Stephen Sommers, 2004), en el que la criatura aparece esporádicamente, aunque con el marchamo futurista propio de los relatos de superhéroes y el steampunk. Su inspiración evidente es la serie de cómics de Alan Moore y Kevin O'Neill The League of Extraordinary Gentlemen (1999-2019, cinco volúmenes), cuyo universo fue llevado al cine en la película del mismo nombre (Stephen Norrington, 2003).
} 
transescribir el mito de Frankenstein, aunque ello queda fuera de nuestro alcance en este artículo $^{10}$.

\subsection{Del texto al architexto}

Nuestro recorrido por el Frankenstein transmedial confirma la presencia y pujanza del mito más que del libro, como dejan ver las siguientes palabras de Jancovich:

Consequently, it is not that Mary Shelley's novel has ceased to inspire filmmakers. On the contrary, as was suggested at the start of this chapter, the novel's influence may be so dispersed that it is almost impossible to capture. Rather than a narrative of decline, it is therefore the case that the most interesting appropriations are by films that do not explicitly invoke the novel, while those films that explicitly establish a relationship often do so in an uninspired bid for respectability or as a simple exercise in branding (2016: 203) ${ }^{11}$.

La pregunta a la que conduce esta constatación, naturalmente, es una variante de la que nos hacíamos al principio: ¿qué es lo que comparten todos estos filmes? La respuesta, desde nuestro punto de vista, es sencilla: un architexto generado a partir del hipotexto fundador por sus derivaciones hipertextuales, convertidas a su vez en hipotextos e intertextos de nuevos hipertextos (el caso de las películas de Whale es muy revelador en este sentido). Para describir este architexto solo tenemos que identificar el paradigma que da cabida a los diferentes y sucesivos sintagmas en que se ha encarnado, es decir, un Frankenstein architextual. Tal paradigma es un patrón narrativo que gira en torno al

\footnotetext{
${ }^{10}$ Por acudir solo a ejemplos del siglo XXI, baste citar una de las novelas finalistas del Booker Prize de 2018, Frankenstein in Baghdad (Ahmed Saadawi), o a la del prestigioso autor británico Peter Ackroyd, The Casebook of Victor Frankenstein (2008). De entre las aproximadamente treinta que declara tener localizadas David Punter (2016), este se ocupa, junto a la ya citada aquí Frankenstein Unboud (Biran Aldiss, 1973), de la primera entrega de Koontz, de Frankenstein's Monster (Heyboer O'Keefe, 2010) y de Brother, Frankenstein (Michael Bunker, 2015). Podemos citar también, por el interés que ofrece su variedad, la recopilación de relatos cortos The Ultimate Frankestein (1992), que Genara Pulido (2017) ha tomado como base para estudiar la pervivencia del mito en la Posmodernidad, aunque dejando de lado otros muchos ejemplos tal vez de más interés. Para la pervivencia del mito en la novela gráfica, véase Murray (2016).

${ }^{11}$ La desaparición de la novela como hipotexto la constataba ya Tropp cuando escribía que en la historia de Frankenstein en el cine «theater and film have supplanted the novel as a source of myth» (1999: 39). Jancovich insiste en la misma idea cuando escribe: «Few, if any, of the films that are associated with Mary Shelley's novel were actually an adaptation of this source text. Many are actually adaptations of other sources, such as plays, other films and comic books. They are also rarely even simply adaptations of these other sources but are rather produced in relation to a range of different intertexts» (2016: 191)
} 
personaje que le da nombre -o, mejor dicho, personajes, pues no olvidemos que en el mito la criatura sin nombre se ha apropiado del nombre del creador- y la acción que emana de ellos. El núcleo de tal acción, naturalmente, es la creación artificial de un ser adánico por parte de una figura prometeica, pero lo que la diferencia de mitos creacionales afines como el de Prometeo o Pigmalión, es la dialéctica que pone en marcha entre creador y criatura. Tal dialéctica está definida por la confrontación, naturalmente heredada del gótico y su dualidad entre héroe y villano, aunque refuncionalizada, esto es, sometida a un proceso de (1) interiorización, (2) domesticación y (3) naturalización: (1) la criatura no es un mero villano ajeno y externo sino un doble o doppelgänger del héroe, Victor, tanto de sus luces como de sus sombras; (2) no queda confinada en un remoto y lejano espacio gótico sino que irrumpe en el ámbito doméstico y ordinario del creador; y (3) su creación no tiene una explicación sobrenatural -como en el otro gran mito de la creación artificial, el del Golem- sino racional o científica. Del gótico también ha quedado de forma residual el tercer vértice del triángulo actancial que define al género, la heroína que solía ser su protagonista, de nuevo refuncionalizada: Elizabeth, la prometida de Victor, por una parte, pasa del centro a los márgenes, pero, por otra, encarna de forma pasiva valores alternativos a los del héroe creador, de forma que su silencio acaba siendo una crítica implícita al ego patriarcal y Romántico que la victimiza.

Es posible articular la dinámica oposicional que define la narrativa frankensteiniana en tres motivos fácilmente reconocibles en el texto fundacional: creación, alienación y rebelión. Victor da vida a la criatura, pero su rechazo y el de la sociedad la aliena, lo que provoca su rebelión. De manera análoga a cómo la creación empareja a creador y criatura, lo mismo ocurre con la alienación (Victor se aliena primero voluntariamente para crear y luego es alienado por la persecución de la criatura) y con la rebelión (Victor también se rebela contra las leyes no solo humanas sino incluso divinas). Y a cada uno de estos motivos corresponde un mitema que lleva la dialéctica creador-criatura a diferentes territorios o ámbitos, reconocibles en las diferentes actualizaciones del mito: dualidad, monstruosidad y transgresión. La primera tiene que ver con el yo individual y se manifiesta tanto en la escisión como en la duplicación: la discrepancia entre lo externo e interno del creador tiene su reflejo especular-que es también un vínculo de humanidad compartida- en la de la criatura, aunque con los términos invertidos. La segunda es social y se explora en términos de la marginalización y animalización que hace un monstruo o deshumaniza tanto al que la sufre como al que la perpetra. La tercera es resultado de la tecnología, que produce un empoderamiento sobrehumano tanto del sujeto que hace un uso inapropiado y disruptivo de ella como de su objeto, al que otorga poderes que lo ponen fuera de todo control. En esta visión de la ciencia, más como amenaza que como promesa, radica, 
como veremos, la conexión architextual de Frankenstein con la ciencia ficción, aunque en la novela la crítica de la ciencia va unida a la denuncia del ego Romántico; como ambas convergen en la misma matriz de Victor, conviene matizar, como ha hecho Clayton (2003), que se censuran más los excesos y aspiraciones desmesuradas del primero que de la segunda. De esta somera descripción no es difícil concluir que el mito de Frankenstein tiene que ver mucho con la identidad (y su precariedad), lo que explica su permanencia en la modernidad: en su dimensión interior o psicológica, en la social o exterior, y en la biológica o relativa a la especie. En la primera explora lo humano, es decir, la especularidad que nos humaniza porque nos permite asumir al otro y su oscuridad como parte de nosotros; en la segunda lo inhumano, la marginación que infrahumaniza a sus víctimas y deshumaniza a sus victimarios; en la tercera, lo posthumano, es decir, el empoderamiento tecnológico que nos sobrehumaniza, que nos sitúa más allá de los límites de lo humano.

Podríamos ejemplificar este paradigma architextual con algunos de los sintagmas del Frankenstein transmedial, pero entonces no tendríamos espacio para abordar ese otro ámbito architextual, el del género de la ciencia ficción, en el que también vamos a rastrear el mito. Deberán bastar algunas consideraciones generales para dar cuenta de las posibilidades que este enfoque permite. La principal es la sustitución, a la hora de estudiar la transmediación, de la dialéctica fidelidad-traición que valora ante todo el primer término por una de repetición y variación que privilegia el segundo, para así concentrarse en cómo sucesivos filmes dan diferentes respuestas a las cuestiones planteadas por el mito. Tal estudio muestra la elasticidad y versatilidad de sus motivos y mitemas, que es lo que explica su constante transescritura y, por ello, su carácter mítico.

(1) La creación puede adoptar las formas y procedimientos más variados, desde lo más rudimentario (la construcción a mano de un amigo perfecto, como en May) a lo más sofisticado, hasta el punto de requerir un equipo (Creature from Blood Cove) o producir ejércitos de criaturas; y puede incluso llegar a no ser científica o material sino imaginativa o literaria (Remando al viento). La alienación puede explorarse en términos de género (Making Mr Right), añadiendo la divergencia de la norma social y moral (The Rocky Horror Picture Show) o la explotación sexual (Frankenhooker), o políticos (El espíritu de la colmena). La rebelión del creador puede tener una causa loable (Mary Shelley's Frankenstein) o destestable (Flesh for Frankenstein), y la de la criatura puede servirse de poderes sobrehumanos (I, Frankenstein) o de unas simples aunque enormes tijeras (Edward Scissorhands).

(2) La dualidad se puede dramatizar en la reanimación casera y múltiple de mascotas (Frankenweenie), en la transferencia mutua de cualidades (Young Frankenstein) o en la proyección de los propios traumas y 


\section{Pedro Javier Pardo}

desequilibrios (Depraved). La monstruosidad puede tener aspecto robótico (los filmes de la Universal) o parecer una horrible deformación congénita (The Post-Modern Prometheus), puede incluso estar disfrazada de una belleza que luego va degenerando, como si de Dorian Gray se tratara (The True Story). El empoderamiento transgresor intenta vencer a la muerte con transplantes cerebrales (Hammer) o porque implica la resurrección de los muertos (The Frankenstein Syndrome), incluso la inmortalidad (The Frankenstein Theory), pero también puede suponer la extinción de la raza humana por la amenaza nuclear (Frankenstein 1970) o de un virus devastador (Frankenstein Reborn).

(3) Además, este corpus tan variado y aparentemente heterogéneo se presta a agrupamientos que permiten establecer interesantes líneas de filiación y estudio. Las categorías transescriturales que hemos aplicado ponen de relieve que las reescrituras siguen más de cerca el architexto que las transficciones, pues la transformación está siempre regulada por la equivalencia, que no es tan importante cuando se trata de expandir o continuar la historia más allá de su final, lo que permite dejar volar la imaginación con mayor libertad. Los desplazamientos que no declaran su filiación con el mito son especialmente valiosos para comprender la dinámica architextual, pues suelen encontrarse más cercanos al architexto que filmes que llevan la palabra Frankenstein en el título, lo que las sitúa a medio camino entre imitación y reescritura, reproducción y transformación, por eso en otro lugar me he referido a ellos como recreaciones (2018).

(4) Más allá de estas tipologías formales, podemos observar tendencias transversales que historizan el desarrollo del mito: ya hemos apuntado su sexualización y explotación erótica que empieza con la Hammer y es casi una constante hasta finales de siglo XX. Otra muy interesante es la feminización no solo observable en el desarrollo de la criatura femenina (que culmina en The Bride, pero empezó ya con el segundo filme de la Universal y continúa en la adaptación de Branagh, pasando por Frankenstein: The True Story), sino en la vocalización de la crítica a la ciencia patriarcal desde presupuestos de género, observable en Making Mr Right, el Frankenstein de Rose o Depraved, en las que la mujer adopta un rol maternal; y que en el de Mercurio ha llegado hasta la feminización de la propia ciencia y la utilización del mito para reflexionar sobre la maternidad.

(5) Finalmente, y tal vez lo más importante, pues es nuestra respuesta final a la pregunta con la que iniciamos esta indagación, para que un filme se considere parte del mito frankensteiniano, no tiene que manifestar todos los motivos y sus mitemas asociados. Lo determinante es la aparición de la dialéctica creador-criatura en cualquiera de ellos: no hay ninguna 
condición más allá de la presencia de estas dos figuras y la dinámica de creación y confrontación que las une, que suele manifestarse en forma de persecución, aunque puede adoptar otras (incluyendo inversiones o subversiones). Nuestra visión es así diferente de la tradicional explicación del mito a través de una serie de invariantes cuya repetición es imprescindible, que la mitocrítica francesa ha desarrollado de manera magistral. Esta visión normativa es insuficiente para dar cuenta del tipo de mito del que nos estamos ocupando aquí, que se presta más a un análisis no tanto de invariantes como de variantes combinables. De su conjugación y, sobre todo, de su mayor o menor número en una obra, surgen diferentes grados de presencia del mito. En su forma plena, el grado más alto, estarán los tres motivos y mitemas (aunque no necesariamente con la misma importancia); en la mínima, habrá al menos uno, la creación (pues este determina las dos figuras cuya dialéctica sí es imprescindible), aunque puede desplazarse fuera del relato y estar así presente in absentia; desde luego, puede haber alienación sin rebelión, o rebelión sin alienación; y, por supuesto, puede privilegiarse uno de los mitemas en detrimento de los otros.

\section{DEL MITO AL GÉNERO: FRANKENSTEIN POSTHUMANO}

\subsection{Ciencia ficción y posthumanidad}

Una vez comprendida la estructura architextual de la trascendencia transmedial de la novela de Mary Shelley, es el momento de abordar su frecuentemente señalada presencia en el cine de ciencia ficción. Para ello, es fundamental entender que el género es también una configuración architextual, pero diferente del mito. Si este se define por un argumento, estructura narrativa o acción, habitualmente en torno a un personaje específico, aquel engloba un conjunto de características no referidas exclusivamente a un personaje o acción específicas, pues pueden incluir también un determinado cronotopo, temas o ideas específicas, una galería de personajes, ciclos o procesos generales, un método o enfoque particular. De hecho, si bien hay géneros que se solapan con el mito, como la ficción policial o la novela picaresca lo hacen con el mito del detective o el del pícaro (lo que no quiere decir que incluso ahí no podamos diferenciar el enfoque mítico del genérico), hay otros como el bildungsroman, el Western, el roman à clef o la novela histórica, donde la ausencia de una estructura narrativa determinada genéricamente deja un margen más amplio a la siempre fructífera interacción de ambas categorías architextuales. Tal es el caso de la ciencia ficción, que se define por su utilización de la extrapolación o especulación científica para racionalizar una presencia extrañante, bien sea en forma de extraño que irrumpe en nuestro mundo contemporáneo, aquí y ahora, o de una visita a un mundo extraño, que puede ser el nuestro en un futuro distante o uno ajeno en un espacio lejano. Al enfatizar esta presencia extrañante estoy siguiendo la teoría del extrañamiento de base científica y con propósito especulativo y 


\section{Pedro Javier Pardo}

no simplemente escapista que Darko Suvin denominó conaissance distanciée o cognitive estrangement en un estudio capital del género (1979), aunque mi formulación dual remite al título del clásico de Robert Heinlein, Stranger in a Strange Land. Si el antecedente de los mundos extraños de la ciencia ficción son las utopías y los viajes fantásticos que se remontan a la Antigüedad, pero que Swift vincula a la exploración y especulación científica en el libro III de Gulliver's Travels (1726), el de los sujetos extraños naturalizados por la ciencia es sin duda Frankenstein. Para muchos historiadores del género, especialmente de habla inglesa (el caso más conocido es el de Brian Aldiss), Mary Shelley es la madre de la ciencia ficción $^{12}$. Esta posición privilegiada de Frankenstein como texto fundador del género ha tenido la paradójica consecuencia de ocultar cómo el mito que también ha fundado puede estar presente en obras que tienen este parentesco genérico de base.

Detectar su presencia exige, naturalmente, deslindar el paradigma narrativo mítico del ADN genérico, como acabamos de hacer. El problema es que ambos parecen mezclarse en una línea temática de la ciencia ficción que explora el tercer mitema del Frankenstein architextual, la transgresión dada por el empoderamiento tecnológico, eso que se ha denominado el complejo de Frankenstein: los peligros de la tecnología, provenientes tanto del científico demente como de la rebelión de la máquina, siendo esta encarnada por diferentes variantes de la criatura como inteligencia artificial, desde un simple ordenador o sistema operativo a una figura humanoide (ciborg, robot, androide). Si el extrañamiento científico proporciona el sustrato genérico común, una especie de grado 0 de la presencia architextual de Frankenstein en la ciencia ficción, podemos discernir, en primer lugar, un grado 1 representado por ciertos relatos de empoderamiento tecnológico (de nefastas consecuencias), en los que no tiene por qué haber una criatura; y, en segundo lugar, un grado 2 en los que este empoderamiento adopta la forma de la creación artificial, que podemos denominar relatos de la posthumanidad. Es aquí donde puede encontrarse el mito que nos eleva al grado 3, pero antes de abordarlo debemos detenernos a clarificar el término posthumanidad.

En 2013 Rosi Braidotti publicó un estudio de gran impacto titulado The Posthuman, en el que postulaba un posthumanismo filosófico, que ya había sido apuntado o formulado por autores como Ihab Hassan a finales del los 70 o Donna Haraway en los 80, como crítica y superación del antropocentrismo del humanismo tradicional, cuya concepción de lo

\footnotetext{
${ }^{12}$ El título del primer capítulo de su Trillion Year Spree (1986) lo deja ya muy claro: «On the Origin of Species: Mary Shelley». Para Suvin (1979), sin embargo, el autor de referencia es H. G. Wells, y, ciertamente, en este convergen las dos líneas genealógicas indicadas: el extraño como creación científica (The Island of Dr Moreau) pero también como extraterrestre (The War of the Worlds), y el mundo extraño como evolución distópica del nuestro (The Time Machine).
} 
humano basada en jerarquías y dualidades del tipo humano/animal, cultura/natura, individuo/especie, intentaba trascender. Pero, como apunta bien Sara Martín (2021: 6-7), mucho antes de eso, el término posthuman había hecho su aparición en la ciencia ficción, concretamente en un relato de H. P. Lovecraft, The Shadow Out of Time (1936), en el que se usa para referirse a los alienígenas que reemplazarán al homo sapiens y, por tanto, a la sustitución de este por una especie posthumana, sea esta extraterrestre o artificial, es decir, creada por el ser humano. Por ello, si se consulta el Posthuman Glossary (2018), David Roden diferencia este posthumanismo que denomina especulativo del crítico: ambos implican una nueva concepción de lo humano, pero el segundo dirige su crítica al área de la cultura y la política, el primero especula sobre el uso de la tecnología y sus consecuencias para la humanidad: «Speculative posthumanists claim that there could be posthumans: that is, there could be powerful nonhuman agents that arise through some human-instigated technological process» ${ }^{13}$. Esto es exactamente lo que hace ya dos siglos planteó Mary Shelley en su novela, que puede ser leída desde esta óptica posthumana, algo que Martín cuestiona con razón por su anacronismo (2021: 5, 9-10), pero Mousley hace de manera admirable amparado en la idea de una prehistoria de lo posthumano en la literatura anterior a la ciencia ficción (2016: 158-159). Más allá de esta lectura retrospectiva de la obra, es evidente que su criatura es el primer ancestro del sujeto posthumano, es decir, de una creación tecnológica, un ente fabricado por el ser humano, cuya humanidad es objeto de debate y cuya existencia cuestiona los límites de lo humano: ¿es máquina/artefacto, o es una nueva forma de vida/humanidad? De esta manera, tal sujeto tiene un efecto transformador del concepto de humanidad en posthumanidad e incluso plantea - por esa posibilidad que tanto aterra a Victor, la de su reproducción con una compañera- la sustitución de la primera por la segunda. Por ello, Mary Shelley, además de ser para muchos el origen de la ciencia ficción, es la fuente indiscutible de los relatos de la posthumanidad, es decir, su paradigma architextual ${ }^{14}$. Y ello no solo en un sentido genérico, es decir,

\footnotetext{
${ }^{13}$ Roden añade: «Another way of putting this is to say that posthumans would be "wide human descendants" of current humans who have become non-human in virtue of a process of technical alteration». Estas palabras apuntan de manera más clara que el posthumanismo especulativo no se limita al campo de la ciencia ficción, sino que también se observa en el área de la investigación tecnocientífica conocida como transhumanismo, que ha llevado a la práctica las hipótesis de la ciencia ficción y busca la mejora del ser humano tanto en sus capacidades físicas como intelectuales a través de la tecnología (véase Martín, 2021: 7). Agradezco mucho a Sara Martín el haberme permitido leer su artículo antes de ser publicado; las páginas referenciadas son las del texto en Word que me ha hecho amablemente llegar.

${ }^{14}$ Véase Eleine Graham Representations of the Post/Human, donde parte de la novela de Shelley para estudiar este tipo de relatos no solo en la ciencia ficción, también en ensayos como el bien conocido de la ya citada Donna Haraway «A Cyborg
} 


\section{Pedro Javier Pardo}

Frankenstein como génesis y modelo de la ciencia ficción de temática posthumana; sino también mítico, es decir, Frankenstein como origen y patrón de una estructura narrativa en la que la dialéctica creador-criatura ocupa una posición central. Ello permite postular un Frankenstein posthumano en la ciencia ficción, que estaría conformado por aquellos relatos de la posthumanidad en los que podemos detectar esta dialéctica: a través de diferentes avatares, la criatura de Mary Shelley se sigue enfrentando a su creador para hablarnos así sobre la posthumanidad.

\subsection{El sujeto posthumano: Blade Runner}

A la hora de diferenciar este ámbito posthumano en la ciencia ficción, nada mejor que empezar asomándonos muy brevemente a una obra en la que la huella mítica de Frankenstein no toma la forma posthumana que nos interesa. Me estoy refiriendo a Solaris (1961), la novela de Stanislaw Lem, llevada al cine primero por Andréi Tarkovski (1972) y luego por Steven Soderbergh (2002). Lem llama la atención sobre la presencia del mito frankensteiniano en su obra a través de una referencia intertextual indirecta, como es característico del tipo de reescritura que hemos denominado desplazamiento: la plataforma espacial desde la que los científicos investigan el desconocido planeta que da título a la novela se llama Prometheus. Esta presencia se activa cuando la proximidad de Solaris tiene la extraña virtud de materializar las fantasías, miedos, obsesiones de los investigadores espaciales, que toman cuerpo en criaturas resucitadas de su pasado, de las que no pueden desprenderse y acaban dando al traste con la misión. El mito se deja sentir no tanto en la mera aparición de estas criaturas, pues no son creaciones tecnológicas sino mentales o fantasmáticas, como en la dialéctica que genera con sus involuntarios creadores; y esta, al menos en el caso del protagonista, posee la dinámica confrontacional que define el mito. De esta manera, si bien el motivo de la creación se ha desplazado tanto que cuesta reconocerlo, los motivos de la alienación y la rebelión, y los mitemas de la dualidad y la transgresión, junto con el cuestionamiento del empoderamiento tecnológico desde el universo femenino que aparecía también en Frankenstein, confluyen en una innovadora y original transescritura, a la altura del reconocido talento de su autor. O tal vez no tan original, pues las confluencias con el filme de ciencia ficción Forbidden Planet (Fred M. Wilcox, 1956), rescatado por Tropp para el mito frankensteiniano (1999: 56-57), son llamativas.

Manifesto» (1985), en mitos como el del Golem y en la propia ciencia. Clayton (2003) ha llamado la atención sobre la deuda de este territorio de la ciencia ficción con Shelley: «Contemporary advocates of AI emphasize many of the same things Shelley did: the emotional vulnerability of this new being, its abandonment in a hostile world, existentially alone, its sheer creatureliness. Turning its artificial origins from a liability to a virtue, writers and filmmakers focus on what humans owe to the things they create» (86). 
Si comparamos las criaturas de Solaris con las de una novela publicada solo siete años después, Do Androids Dream of Electric Sheep? (1968), escrita por otro grande de la ciencia ficción, Philip K. Dick, la diferencia es evidente. Los androides o andys Nexus- 6 son productos tecnológicos de la Rosen Corporation, robots orgánicos casi imposibles de diferenciar de los humanos, como es el objetivo declarado de la compañía; tanto que hace falta una prueba de empatía (Voight-Kampff Test) para detectar la diferencia. De hecho, el cazarrecompensas de Los Ángeles Rick Deckard que debe retirar a los Nexus-6 escapados, antes de hacerlo debe asegurarse de que la prueba funciona con ellos para poder así detectarlos. La novela es por tanto un relato de la posthumanidad, pues presenta un mundo en el que la tecnología ha dado lugar a una nueva concepción de lo humano que incluye no solo creaciones humanizadas sino humanos deshumanizados. Plantea así una transformación de la humanidad en las dos direcciones que ya estaban sugeridas en Víctor y su criatura: la humanización de la máquina (visible sobre todo en los androides femeninos, la cantante de ópera Luba Luft y Rachael) y la mecanización del ser humano (visible sobre todo en el otro cazarrecompensas, Phil Resch, y en Iran, la mujer de Deckard, con su compulsivo uso de los tres dispositivos tecnológicos que parecen regir la vida de los humanos: la empathy box, el Penfield mood organ y la televisión). A este respecto, lo más interesante es que la trama de detección tomada del género policial es también de desarrollo personal de su protagonista, que pasa de asesinar androides a empatizar con ellos y abandonar su trabajo, lo que justifica la llamativa descripción de la novela como «a bildungsroman for the cybernetic age» (Galvan, 1997: 414). En este sentido, puede interpretarse su peripecia como la del despertar de la conciencia posthumana, en cuanto que Deckard amplía su concepción de lo humano para incluir no solo a los androides sino incluso a los animales eléctricos: «Electric things have their lives, too» (Dick, 2003: 108). El episodio final en Oregon, en el que parece asumir el papel de Mercer, quien da nombre a la religión del mercerismo, lo convierte, además, en una especie de mesías de la nueva posthumanidad.

La novela Philip K. Dick nos sirve para entender la presencia de lo posthumano en la ciencia ficción, pero, como este breve comentario pone de manifiesto, no la del mito de Frankenstein. Si Lem ilustra el mito sin lo posthumano, Dick ilustra lo posthumano sin el mito. Sin embargo, encontrar una obra en la que convergen ambos no requiere ir muy lejos, basta con acudir a la transmediación de la novela al cine. Blade Runner (Ridley Scott, 1982), una de las películas más influyentes en la historia de la ciencia ficción cinematográfica, mantiene la estructura básica de acción y actantes del original literario, pero lo somete a un profundo proceso de reescritura, resultado en gran medida de intervenciones sucesivas en el guion a lo largo de un dilatado período de tiempo que lo fueron alejando 


\section{Pedro Javier Pardo}

del libro ${ }^{15}$. Muchas de las transformaciones específicas que opera, que no tenemos tiempo de anotar, responden a una lógica reescritural de empoderamiento del replicante (que es como se denominan ahora los androides Nexus), además de a una romantización de los personajes y trama de la novela. Tal empoderamiento resulta, en última instancia, de la mediación del mito de Frankenstein en el proceso de transmediación, es decir, de la superposición del architexto frankensteiniano sobre el hipotexto de Dick. La superposición es observable en la adición de una serie de escenas a través de las cuales se articula la dialéctica creadorcriatura ausente en la fuente literaria, en virtud de las cuales el personaje del replicante Roy Batty (Irmgard Baty en la novela) no solo cobra un protagonismo del que carecía por completo en ella, sino que emerge como sujeto posthumano. Tales escenas son los encuentros entre Batty como criatura con diferentes avatares del creador:

(1) Encuentro Batty-Chew/Sebastian. Hannibal Chew es fabricante de ojos para la Tyrell Corporation, de modo que es una especie de subcreador o creador de segundo grado, y su encuentro con Batty tiene la función primordial de poner en marcha la dinámica de confrontación en los mismos términos de persecución del creador por parte de la criatura que adopta en Frankenstein. Tal persecución lo llevará luego a J. F. Sebastian, un segundo subcreador por su condición tanto de ingeniero de la misma corporación como de constructor de autómatas y juguetes humanoides con los que intenta mitigar su soledad. El asesinato de ambos prefigura el del creador, pero, además, como este, está al servicio de la reflexión que propone la criatura replicante. Si en el caso de Sebastian está implícita en la marginalidad y las carencias emocionales que este comparte con el androide, en el de Chew, Batty llama la atención sobre los ojos y la visión («If you could see what I have seen with your eyes»), tan importante en todo el filme desde ese plano inicial de una pupila que refleja la ciudad, y que imaginamos pertenece a uno de los replicantes, posiblemente Batty, volviendo a la tierra. Los ojos como símbolo de la agudeza visionaria o metáfora de la lucidez, pero también como lugar del alma (el VoigtKampff Test utiliza los ojos), dan cuerpo a la paradoja central de la película de que los no humanos, que no tienen alma, son los que mejor ven a la humanidad, porque son «more human than human», como reza el lema de

\footnotetext{
${ }^{15}$ Véase Frentz y Hocker (1994) y Kolb (1997) sobre este proceso, que empieza con Hampton Fancher comprando los derechos de la novela en 1978 (y escribiendo un primer y breve tratamiento de la historia) y prosigue a través de varias productoras y cambios del guion, en el que al final interviene de forma decisiva David Peoples, quien sigue cambiando cosas incluso durante el rodaje. El proceso, como es bien sabido, se extendió a la posproducción: ante las negativas reacciones de las previews, se modificó el final y se añadió la voz over de Deckard. El montaje original se restituyó primero en el director's cut aparecido en 1992 y luego en el final cut de 2007.
} 
la Tyrell. Además, en este primer encuentro Batty empieza producir un discurso propio y articulado que lo promoverá a la posición de sujeto posthumano. Llegará incluso a citar un poema de William Blake que remite indirectamente a Frankenstein y es, por ello, un marcador intertextual de su presencia architextual ${ }^{16}$.

(2) Encuentro Batty-Tyrell. El encuentro con Eldon Tyrell, el creador intelectual de los replicantes y, además, dueño y señor de la corporación que en la película sustituye a la Rosen (un detalle importante que apunta a la evolución del creador hacia la figura del magnate o potentado que asume su papel en otras obras), supone la irrupción definitiva de Batty como sujeto discursivo plenamente desarrollado, lo mismo que ocurre con la criatura en su encuentro en el mar de hielo con Victor, en el que hace pensar el androide cuando se dirige a Tyrell como padre y Dios de la biomecánica. Como en el caso de la criatura, tras sus actos criminales no hay sino una humanidad caída: no son monstruos, sino un reflejo especular de los humanos (como subraya el término replicante), atormentados por la angustia de su mortalidad, por la certeza de que la extinción se aproxima, por el deseo de vivir más. La duplicación se extiende también a la alienación, que podemos detectar no solo en las criaturas en perpetua huida sino en el aislamiento del creador en su torre, cuyo interior cobra forma gótica y se antoja por ello equivalente a la buhardilla en la que Victor se aísla del mundo durante su creación. Y es significativo, finalmente, que la destrucción del creador que es el clímax de la rebelión de la criatura se produzca hundiéndole los ojos, la misma forma en que Leon está a punto de matar a Deckard, lo que nos remite de nuevo al tema de la visión y caracteriza tal rebelión como castigo por su ceguera a las consecuencias de su acto de creación. Tal ceguera, que es la de Victor, queda subrayada por la miopía que ponen de manifiesto las enormes y anacrónicas gafas de culo de vaso que luce Tyrell: frente a los ojos brillantes e iluminados de los replicantes, que revelan su visión lúcida respecto a la condición humana, la ceguera o miopía de los humanos.

\footnotetext{
${ }^{16}$ Como explica Desser (1997: 64-65) en un detallado e iluminador inventario de los paralelismos entre Blade Runner y Frankenstein, aunque con cierta dispersión y falta de coherencia por el afán de llevarlos demasiado lejos, la forma en que Batty cambia la cita del poema America: A Prophecy para hacer que sus ángeles caigan en vez de levantarse sugiere que Batty se identifica con el ángel caído, es decir, con Satán, al igual que la criatura de Shelley, que ha leído Paradise Lost, y esta obra es por ello un importante intertexto tanto en Frankenstein como en Blade Runner. De hecho, Desser argumenta que media la presencia de la primera en la segunda, lo que le lleva a postular que Batty, como la criatura, es tanto Satán como Adán e incluso Eva, en una multiplicación de roles que extiende a Deckard y cuyo exceso nos parece que resta valor a su análisis. Parece más sensato asociar a Batty con Satán, y a Deckard y Rachael con Adán y Eva, expulsados del paraíso al final y listos para fundar una nueva humanidad, como confirmará 2049.
} 
(3) Encuentro Batty-Deckard. Con la muerte del creador, Deckard asume el papel de perseguidor de la criatura que corresponde a Victor al final de la novela de Shelley, para instaurar así en el filme la doble dinámica de persecución que define la dialéctica creador-criatura del mito. Y esa persecución conduce a un encuentro que, a diferencia de la novela, es prolongado y climático, y que termina con Deckard derrotado. Pero, en contra de lo previsible, aunque no tanto si tenemos la novela de Shelley en mente, Batty le perdona la vida y pronuncia antes de morir el memorable monólogo Tears in the rain, que completa su proceso de humanización y vocalización discursiva como sujeto posthumano iniciado en el primero de esta serie de encuentros. Y lo hace, muy significativamente, volviendo al tema de su obertura, la visión («I've seen things you people wouldn't believe» $)^{17}$; y a la experiencia de la muerte y la pérdida que entraña, como con Tyrell. Pero ahora hay un elemento nuevo respecto a lo ocurrido con este, como es la capacidad de perdonar y aceptar la muerte propia poniendo en valor la vida ajena (esta explicación añadida como voz over de Deckard en la posproducción nos parece la mejor) y, por tanto, de evolucionar y alcanzar la humanidad plena, simbólicamente sancionada por la paloma que Batty deja escapar de sus manos al morir, cual alma que abandona su cuerpo. Ello le da una dimensión no solo humana, sino también mesiánica, como portador de un mensaje de amor a todos los seres vivos, tanto los de la vieja como los de la nueva forma de humanidad, y por tanto para la posthumanidad. Esta dimensión es ratificada por la simbología religiosa que Desser detecta perfectamente: su muerte es asociada con la de Cristo por el clavo atravesando su mano y la paloma que representaría no solo su alma sino también el Espíritu Santo (1997: 56). La película transfiere así a Batty la dimensión mesiánica que en la novela poseía Deckard, pero la atención con que este lo escucha y su decisión inmediata de escapar con la replicante Rachael parece sugerir que ha cambiado su forma de ver a los androides y, en ese sentido, ha sido redimido por el sacrificio de Batty para convertirse así él también en un sujeto posthumano, algo confirmado porque a ello sigue el descubrimiento de su propia condición de replicante. Batty es el mesías de los replicantes

\footnotetext{
${ }^{17}$ Justo antes, y de forma un tanto irónica, Pris se pinta los ojos como si llevara un antifaz y Roy juega con los ojos falsos de Sebastian. Clayton (2003) ve una conexión entre este tema de la visión y la pesadilla de Victor Frankenstein en la novela de Shelley, en la que ojos sin cuerpo lo atormentan, o la importancia de los ojos en el proceso de creación (89). El análisis de Clayton de los paralelismos entre Frankenstein y Blade Runner (88-91) es muy acertado, pues recoge la conexión architextual tanto del relato de las posthumanidad como de la dialéctica creadorcriatura.
} 
que muere para salvar/redimir a la (post)humanidad representada por Deckard, quien podemos imaginar es su Adán ${ }^{18}$.

De la aparición de la conciencia posthumana en la novela de Dick hemos pasado a la emergencia del sujeto posthumano como resultado de la dialéctica frankensteiniana presente en el filme. En este, siguiendo también al texto fundador, juega un papel importante el elemento femenino, en este caso representado por Rachael. Es ella la que da voz a la crítica de la tecnología y sus negativas consecuencias como víctima femenina de la misma, puesto que ignoraba su condición de androide hasta que Deckard se la descubre, y contribuye a desplazar a los replicantes del rol de victimarios al de víctimas. Rachael cuestiona la separación humanoreplicante y afirma que retirar a estos es como asesinar a aquellos, lo que hace que Deckard empiece a verse como una máquina de matar y contribuye así a su redención. Rachael es la criatura femenina que Victor no llega a terminar, que ya se había convertido en Eva artificial en L'Ève future (Auguste Villiers de l'Isle-Adam, 1886) y hecho su entrada en el cine de ciencia ficción de manera muy temprana con Metropolis (Fritz Lang, 1927), muy influyente en Blade Runner por la visualización retrofuturista de la distopía urbana. La progenie de Evas posthumanas será abundante tras el filme de Scott, como veremos más abajo, en armonía con la

\footnotetext{
${ }^{18} \mathrm{La}$ emergencia del sujeto posthumano, que en literatura debe mucho a los relatos de robots de Isaac Asimov, otro maestro del género, se deja sentir inmediatamente después de Blade Runner en Terminator (James Cameron, 1984) y Robocop (Paul Verhoeven, 1987), que se han relacionado insistentemente con el mito frankensteiniano, pero cuya relación es muy lejana, de grado 1 (al igual que la de otros filmes como The Thing [John Carpenter, 1982] o Alien: Resurrection [JeanPierre Jeunet 1997]). Más cercano (en el grado 2) se encuentra Bicentennial Man (Chris Columbus, 1992), basada en The Positronic Man (1992), novela del propio Asimov y Robert Silverberg, en la que aparece la figura del creador como Rupert Burns, al que se dirige el robot protagonista Andrew, como ocurre también en A. I. Artificial Intelligence (Steven Spielberg, 2001), basada en un relato de Aldiss, donde se narra el encuentro del niño androide David con su creador el profesor Hobby; en ambos casos, sin embargo, los encuentros no llegan a convertirse en dialéctica, pues el énfasis recae en la criatura casi exclusivamente. La presencia de un creador junto a la criatura posthumana no es, por tanto, suficiente para postular tal dialéctica, como no lo es tampoco la promoción de la criatura desde su posición inicial de objeto a la de sujeto; un caso paradigmático de este proceso sin mito frankensteiniano sería WALL-E (Andrew Stanton, 2008). La dialéctica, y con ella el grado 3, sí puede encontrarse en dos filmes de ciencia ficción española, una asociación que por su escasez parece un oxímoron: Eva (Kike Maíllo, 2011) y Autómata (Gaby Ibáñez, 2014), clara heredera de Blade Runner en la dinámica de la persecución y el desplazamiento del creador al papel de perseguidor. También puede encontrarse en otros dos filmes españoles que abandonan la temática posthumana para orientar el mito hacia la resurrección: La piel que habito (Pedro Almodóvar, 2011) y Proyecto Lázaro (Mateo Gil, 2016).
} 
feminización del mito que hemos constatado en las transmediaciones, observable en otro filme de esos mismos años, The Bride (1985). En una década que brilla por la ausencia de adaptaciones del hipotexto de Mary Shelley (con excepción hecha del telefilme de bajo presupuesto ya mencionado), solo esta película, junto con Making Mr. Right (1987), dan continuidad al mito de Frankenstein en el cine. En tal compañía, no es descabellado considerar Blade Runner la expresión más acabada del mismo para así proponerlo, al igual que hice en un trabajo previo (2008), como el Frankenstein de los 80; aunque, por supuesto, un Frankenstein posthumano.

\subsection{El héroe posthumano: Blade Runner 2049}

Con el salto de la página a la pantalla Batty y los replicantes saltan también de los márgenes al centro y desarrollan su capacidad emocional, intelectual y física, un proceso al que nos hemos referido como empoderamiento del replicante. Pero Batty sigue siendo heredero del villano gótico, como la criatura de Frankenstein, pese a que su discurso y su acción finales le acaban confiriendo una cierta dimensión heroica y hasta mesiánica. Ello pone en marcha un proceso de heroicización (similar al que han experimentado otros villanos de origen gótico, el caso más llamativo es tal vez el del Hannibal Lecter de Thomas Harris) que culmina en la secuela estrenada en 2017, Blade Runner 2049, con Ridley Scott en la producción, Hampton Fancher en la creación (con la colaboración de Michael Green en el guion) y con la dirección a cargo de Denis Villeneuve (The Arrival, Sicario, Enemy, Incendies...). Con este trío de ases la película no podía sino ser otra obra maestra, que en absoluto desdice de su modelo y consigue eso tan difícil que es refutar la verdad universalmente admitida de que segundas partes nunca fueron buenas. El filme conjuga la libertad creativa y de innovación respecto de su hipotexto con la continuidad y el perfecto entendimiento del mismo; y, si bien tal hipotexto es fílmico, está enriquecido por la literatura, tanto por el texto de Dick que sirvió de modelo primigenio como por los hipertextos de K. W. Jeter generados por Blade Runner. Todos juntos conforman un auténtico ciclo transficcional, pues se basa en una dinámica expansiva, y transmediático, pues utiliza diferentes medios que incluyen también el video juego y la novela gráfica ${ }^{19}$. En este contexto, lo más interesante de 2049 como

\footnotetext{
${ }^{19} \mathrm{Ya}$ antes del estreno de Blade Runner, la novela de Dick volvió a publicarse con el título del filme, publicitándola como de interés para los fans del mismo, y empezando así la confluencia de ambas en una especie de architexto común, consolidado en una secuela literaria autorizada, pues partió de la película, pero incorporó aspectos de la novela: Blade Runner 2: The Edge of Human (1995). A esta seguiría una tercera (1996) y cuarta (2000) entregas, lo que configura una trilogía escrita por K. W. Jeter, amigo de Philip K. Dick, en la que se fusiona la novela de este con la película de Scott, al igual que hará el videojuego Blade Runner de 1997. Además, la novela se adaptó al cómic en 1982 (con una versión autorizada y otra paródica), y el filme en 2009. Todo ello convierte Blade Runner en una narrativa
} 
transficción es que sigue utilizando architextualmente a Frankenstein, colocando la dialéctica creador-criatura en el centro de la película, tanto de su desarrollo argumental como de su estructura actancial: el creador es el antagonista principal de la criatura protagonista, pero esta ahora es más inocente y empática, el creador más alienado y perverso. Se produce así la culminación del proceso de empoderamiento del replicante al convertirlo no solo en sujeto, como en Blade Runner, sino incluso en héroe posthumano, y tanto en su variante masculina como femenina. La amenaza para la humanidad ya no proviene de la criatura posthumana sino del creador inhumano o deshumanizado, que es el que asume ahora el papel de villano gótico.

(1) De Tyrell a Wallace: creación y procreación. El creador en 2049 carece ya de la dimensión científica que tenía en Blade Runner para asumir en exclusiva la de magnate que se apuntaba allí: es el CEO de la corporación que lleva su nombre y ha sustituido a la Tyrell como fabricante de replicantes (o angels, como los llama él mismo, jugando así con la intertextualidad miltoniana y religiosa). Niander Wallace es un claro emblema del capitalismo monopolista, multinacional y descontrolado, aunque pasa por filántropo, y en las dos escenas en las que tiene lugar su confrontación con la criatura, primero K pero luego el propio Deckard, aparece destruyendo más que creando: en la primera, a una androide recién nacida, en la segunda a la copia de Rachael clonada para seducir a Deckard $^{20}$. En este sentido, es muy significativo que la miopía de Tyrell se ha convertido en ceguera y que su rol creador se ha desplazado a otro personaje, Ana Stelline, quien humaniza con los recuerdos que fabrica a los replicantes y los contempla con empatía. Pese a la ausencia de esta dimensión en Wallace, es fácil identificarlo con la figura frankensteiniana en su aspiración prometeica, caracterizada en los mismos términos de obsesión y exceso, empoderamiento y transgresión; pero tal aspiración ya no gira en torno a la creación de vida artificial sino a la capacidad de procreación de la misma, con un móvil económico-político (a saber, los evidentes beneficios y el poder que una nueva generación de androides

transmedia, es decir, un ciclo de imitaciones y expansiones sucesivas architextual, multiautoral y transmedial, cuya última entrega es 2049, que, además, cuenta con tres precuelas en forma de cortometraje. Estas pueden visualizarse desde Off-world: The Blade Runner wiki (https://bladerunner.fandom.com/wiki/Blade_Runner).

${ }^{20}$ Lo mismo ocurría en una de las precuelas de 2049, el corto de Luke Scott (hijo de Ridley Scott) en el que sacrifica a un replicante, en este caso masculino, para demostrar que son inofensivos. La predilección de Wallace en el filme por replicantes féminas apunta a una soterrada misoginia que ha sido un tema recurrente a la hora de analizar Frankenstein y su victimización del cuerpo femenino (los asesinatos de Justine y Elizabeth), de la que sacará partido la ya comentada explotación erótica del mito, con su predilección por víctimas (o criaturas) femeninas ligeras de ropa. 
capaces de reproducirse le reportarán). Su obsesión por crear replicantes con capacidad reproductiva introduce un nuevo tema que recorre toda la película e incide en su humanización: la capacidad de generar vida (más que de empatía) aparece como la clave de lo humano; la deconstrucción de la dualidad born/made formulada por $\mathrm{K}$ es ahora donde reside un nuevo salto hacia el sujeto posthumano. Y la frustración de esta aspiración desencadena la persecución de la criatura, del hijo perdido de Rachael y Deckard que contiene en su cuerpo la explicación genética de esa capacidad reproductiva, aunque su búsqueda pasa por Deckard y conduce finalmente a la confrontación con K. Si estos personajes desplazan a la criatura perseguida, la persecución tampoco la realiza directamente el creador, sino que se transfiere a su brazo ejecutor, la replicante Luv (un nombre que sugiere irónicamente love pero también el miltoniano Lucifer); de forma que su combate final con $\mathrm{K}$ es una versión desplazada del enfrentamiento climático entre creador y criatura.

(2) De Deckard a K: heroísmo posthumano. Naturalmente, lo más llamativo de 2049 en un primer momento es que un replicante presentado desde el principio como tal asuma el papel de protagonista, no solo de la trama policial que busca al hijo perdido de Rachael y Deckard sino de una trama adicional superpuesta a esta, aunque complementaria, que podemos denominar de los orígenes. En el curso de su investigación, K encuentra indicios para creer que él es ese hijo, lo que no solo le da una identidad como nacido y por tanto humano que lo saca de la esclavitud y niebla existencial que envuelve a los replicantes, sino como elegido, mesías de una emergente y rebelde posthumanidad, con evidentes ecos crísticos (su nacimiento es descrito como miracle y tiene que ser escondido para salvar su vida, que transcurre ajena a su destino mesiánico hasta que llega su momento; se crea así un claro paralelismo con la vida de Jesús narrada en la Biblia). Ello le otorga una dimensión heroica que lo convierte no solo en sujeto sino en héroe posthumano, profundizando así en el empoderamiento de la criatura que Blade Runner imponía ya sobre Do Androids. Este papel heroico se ve reforzado por la superposición de otro architexto ajeno al frankensteiniano, el arquetipo del héroe, particularmente en su actualización caballeresca que va de Perceval el Galés a Amadís de Gaula, articulado en una serie de motivos recurrentes detectables en 2049: (1) los orígenes desconocidos pero extraordinarios que determinan tanto como anuncian el destino heroico (aquí remiten al orfanato de San Diego en el que se crio); (2) el token o señal que permite recuperar esos orígenes e identificar al héroe como tal (aquí el caballo de madera con su fecha de nacimiento: 6.10.21); (3) su carácter de elegido para una misión redentora concebida como aventura guardada para él (aquí liderar la revolución de los replicantes esclavizados). Este architexto, sin embargo, recibe un tratamiento irónico al final: K no es el hijo de Rachael porque los recuerdos que lo identifican como tal son implantados y 
pertenecen a otro, el auténtico mesías; de hecho, a otra, Ana Stelline, lo que añade un giro subversivo del arquetipo heroico al feminizarlo y por tanto alejado del heroísmo tradicional. Ello, sin embargo, no subvierte la posición heroica de K, pues muere para salvar a Deckard y su hija Ana de Wallace y permitir su encuentro: esa era la misión que le estaba reservada y en la que reside su heroísmo. La música de la banda sonora de Blade Runner que oímos mientras K agoniza en la nieve es un eco intertextual que vincula los finales de ambas películas, y a $\mathrm{K}$ tanto con Deckard salvando a Rachael como con Batty salvando a Deckard. Si no es el mesías, al menos es el apóstol cuyo sacrificio permitirá el advenimiento de la posthumanidad $^{21}$.

(3) De Rachael a Ana/Joi: posthumanidad aumentada. El elemento femenino que participa en el mito de Frankenstein desde sus orígenes cobra en 2049 mayor relevancia por la introducción de la temática de la reproducción. La película da cuerpo a la profecía contenida en la intertextualidad miltoniana de Blade Runner y convierte a Deckard y Rachael en los Adán y Eva de una nueva posthumanidad en la que la separación entre lo mecánico y lo humano se diluye: Rachael es la primera replicante capaz de crear vida de manera biológica y no artificial; su criatura Ana ya no es fabricada sino nacida, lo que impide considerarla como una máquina. Estamos ante una posthumanidad aumentada, y no solo por su capacidad reproductiva sino también por su conciencia política. La dimensión política del filme puede ya intuirse en una soterrada conciencia feminista consistente no tanto en su vocalización reivindicativa como en la feminización del architexto. No solo Rachael y Ana son el alfa y omega de una trama que arranca con la primera madre replicante y se cierra con la hija mesiánica, sino que también está Freysa, líder del Replicant Freedom Movement, o Joshi, la jefa de K en la policía, e incluso la asesina Luv. Pero lo más distintivo de la politización del architexto frankensteiniano que caracteriza, junto con su anexión al heroico, su

21 El giro irónico a esta trama de los orígenes está sugerido por la rica intertextualidad literaria de que hace gala la película, en la que podemos detectar el mismo neovictorianismo posmoderno que veíamos en las transmediaciones del mito frankensteiniano en el siglo XXI. El orfanato Morrillcole contiene evidentes ecos de Oliver Twist de Dickens, y Dickens conduce al relato de los orígenes en Great Expectations; pero, esta trama identitaria victoriana está contemplada e ironizada a través de la modernidad de Kafka (el K perdido en el laberinto burocrático y existencial de El castillo) y la posmodernidad de Nabokov (los malentendidos que son centrales en la trama de Pale Fire, el libro de cabecera de K). K as así el depositario de una riquísima intertextualidad literaria que va de la ficción caballeresca a Nabokov, pasando por Dickens y Kafka. Sobre la primera y sus motivos recurrentes que son relevantes en 2049, véanse, entre otros, Köhler (1970/1990), Stevens (1973), o Cacho Blecua (1979); y sobre el arquetipo del héroe, naturalmente, Campbell (1968/1972). 


\section{Pedro Javier Pardo}

tratamiento en 2049 es llevar la rebelión del plano individual o existencial al colectivo de clase y no de género, para convertirla en una revolución contra la esclavitud, la opresión y la segregación de tintes racistas y supremacistas (observables en el apelativo despectivo que se utiliza contra los replicantes: skins). «A revolution is coming», declara Freysa, y así lo anticipa una de las precuelas del filme, el corto de animación manga, donde el blackout provocado por los replicantes tiene similares fines políticos (el que se centra en el replicante Sapper Morton muestra la opresión y el racismo). En esa capacidad de lucha, de hecho, radica también su nueva y aumentada posthumanidad, como ponen de manifiesto las palabras de Freysa: «Dying for the right cause is the most human thing we can do». Y así lo dramatiza no solo el sacrificio de K, sino el de Joi, la mujer hologramática o virtual generada por un programa informático, digital en vez de robótica, pero que adquiere identidad y humanidad a partir de lo que parece su amor verdadero - pese a programado y de contornos claramente patriarcales- por K. Joy aumenta la posthumanidad en un tercer sentido: lleva lo posthumano a la esfera de la realidad aumentada por la que, tal vez, discurran sus caminos en el futuro ${ }^{22}$.

\section{CONCLUSIÓN: CONTINUARÁ...}

Si Rachael es capaz de crear vida mediante la procreación biológica y Ana lo hace mediante la creación artística (recordemos que su labor no es muy diferente de la de un autor que inventa historias para dotar de biografía y recuerdos a los replicantes), ambas nos remiten a los territorios en los que el mito de Frankenstein parece haberse implantado firmemente en la ciencia ficción fílmica del siglo XXI. Su segunda década, muy fructífera en transmediaciones tanto cinemáticas como televisivas, tal y como hemos visto, lo ha sido también en relatos frankensteinianos de

22 El antecedente inmediato de Joi es Samantha, el sistema operativo que protagoniza Her (Spike Jonze, 2013), donde se utiliza al margen de conexión alguna con el mito de Frankenstein para explorar la naturaleza del amor. Esta conexión sí existe en Transcendence (Wally Pfister, 2014), donde la criatura se convierte en un sistema operativo en el que el creador vacía o descarga su cerebro/identidad (el proceso de duplicación o especularidad llevado al extremo, aquí vinculado con el de resurrección), dando lugar a una combinación de inteligencia artificial e inteligencia humana (planteando las consabidas preguntas sobre monstruosidad o humanidad), que nos conduce al mismo territorio de la posthumanidad (en el que se exploran las consecuencias perniciosas de la tecnología sin control). Ciertamente la fusión creador-criatura en un ente no corporal da un giro novedoso a los motivos del mito, pero se exploran igualmente los tres mitemas de Frankenstein y se incluye la crítica femenina al complejo de Frankenstein. Naturalmente, la dramatización de este complejo en la creación de un superordenador que acaba estando fuera de control remiten a un filme capital en la historia de la ciencia ficción cinematográfica 2001: A Space Odissey (Stanley Kubrick, 1968), basado en los relatos de Arthur C. Clarke (especialmente «The Sentinel», 1951). 
temática posthumana: The Machine (Caradog James, 2013), Ex Machina (Alex Garland, 2014), Uncanny (Matthew Leutwyler, 2015) y Morgan (Luke Scott, 2016). Todos ellos, que no podemos comentar en detalle aquí por obvias razones de espacio, tienen en común la feminización del mito: en tres de ellos la criatura es femenina y en el cuarto (Uncanny) hay una mujer que triangula la dialéctica creador-criatura porque se centra en la posibilidad de reproducción posthumana, que al final se hace efectiva en un embarazo. Este interés en la reproducción que tan importante es en 2049 también aparece en una película de ciencia ficción posterior a esta, pero no de temática posthumana, y por tanto con un parentesco más lejano o de menor grado. Me refiero a High Life (Claire Denis, 2018), donde aparece una doctora de claros ecos frankensteinianos en su compulsiva y prometeica persecución de la reproducción biológica («I am devoted to reproduction», dice en cierto momento) a bordo de una nave espacial sin destino ni futuro claros. A diferencia de esta última, todas las anteriores giran en torno a la dialéctica creador-criatura, cada una añadiendo un énfasis o temática distintivos.

Si en Uncanny es la reproducción, The Machine insiste en la resurrección, con el cerebro como lugar de la memoria y la identidad, más la transformación de la criatura en una sofisticada arma de guerra; esto último ocurre también en Morgan, en la que, además, el tema de la humanidad de la criatura se vincula al de la relación paterno-filial, la educación y el debate entre lo natural y lo cultural; finalmente, en $E x$ Machina, cobra primacía la temática de género, con el mito de Pigmalión más que el de Prometeo como intertexto, y con una criatura concebida como femme fatale, víctima al tiempo que verdugo de un villano gótico que es su creador. A este (Nathan) y su criatura femenina (Ava, una evidente variante de $E_{v a}$ ), se les une un tercero en discordia (Caleb), que es invitado como testigo para ponerla a prueba e introduce un esquema triangular en la dialéctica creador-criatura, lo que nos remite al triángulo gótico que estaba también en Frankenstein, aunque con interesantes matices aquí. A los temas prometeicos e identitarios habituales se añaden cuestiones de género: los estereotipos patriarcales (la mujer que utiliza su belleza para manipular como único recurso, la mirada masculina que comodifica a la mujer), la explotación sexual (por parte de un creador narcisista que abusa de las androides femeninas, especialmente su criada Kyoko) y el empoderamiento femenino (la liberación final del sometimiento al creador y la autoafirmación o independencia que supone prescindir también de Caleb).

Ex Machina es posiblemente la exploración más original y sofisticada del Frankenstein posthumano en la pasada década, junto con una serie de TV que lo lleva en una dirección radicalmente diferente, Westworld (Jonathan Nolan y Lisa Joy, 2016, 3 temporadas hasta el momento). En ella el creador aparece caracterizado como autor y la dialéctica creador-criatura sirve para articular una reflexión sobre la narrativa y la ficción, lo que da 
como resultado lo que podríamos calificar como un Frankenstein meta. Esta dialéctica aquí está encarnada por Robert Ford, interpretado por Anthony Hopkins, el creador del parque temático Westworld habitado por cientos de androides que permiten a sus usuarios vivir y no solo leer o ver historias de ficción ${ }^{23}$; y por Bernard Lowe, su ayudante, que va a descubrir que es su criatura en el desarrollo de la primera temporada. La dimensión metaficcional de esta dialéctica, que ha estudiado acertadamente Miguel Sebastián (2018), está muy bien expresada por el cartel en el que Ford aparece moviendo los hilos de Bernard como si este fuera un títere, y es explorada en muchas reflexiones y referencias a la narrativa y la ficcionalidad a lo largo de la primera temporada. En ella Ford aparece como autor de la narrativa maestra que rige las micronarrativas de cada androide, que solo se desvela del todo en la segunda temporada, muy inferior en calidad a la primera; y que en la tercera sale del parque temático para transferirse a un gigantesco ingenio de inteligencia artificial, Roboam, capaz de predecir el futuro de todos los habitantes del planeta y fabricado por los hermanos Serac. La reflexión metaficcional se extrovierte para aplicarse al mundo real y presentar a los seres humanos como personajes de una narrativa maestra controlada ahora por Engerraund Serac, que adopta así el rol frankensteiniano de Ford, lo que equipara humanos a androides. El regreso de Bernard al parque temático al final hace pensar que la serie volverá a sus orígenes en la siguiente temporada. Pero, sea como fuere, nos permite cerrar este ya excesivamente largo trabajo con la única conclusión posible: Continuará...

\section{Bibliografía CITADA}

ALDISS, Brian (1986), Trillion Year Spree, London, Gollancz.

Braidotti, Rosi (2013), The Posthuman, Cambridge, Polity Press.

CACHO BlECUA, Juan Manuel (1979), Amadís: heroísmo mítico y cortesano, Madrid, Cupsa/Universidad de Zaragoza.

Campbell, Joseph (1972 [1968]), The Hero with a Thousand Faces, Princeton, Princeton UP.

Clayton, Jay (2003), «Frankenstein's Futurity: Robots and Replicants», en E. Schor (ed.), The Cambridge Companion to Mary Shelley, Cambridge, Cambridge University Press, págs. 84-99.

DENSON, Shane (2014), Postnaturalism: Frankenstein, Film, and the Anthropological Interface, Bielefeld, Transcript.

Desser, David (1997), «The New Eve: The Influence of Paradise Lost and

Frankenstein on Blade Runner», en J. B. Kerman (ed.), Retrofitting Blade

\footnotetext{
${ }^{23}$ En realidad, la idea estaba ya planteada en una película del mismo título (en español Almas de metal) estrenada en 1973, dirigida por Michael Crichton y protagonizada por Yul Brynner, pero en la que tanto la dialéctica creador-criatura como la reflexividad metanarrativa están ausentes.
} 
Runner. Issues in Ridley Scott's "Blade Runner" and Philip K. Dick's "Do Androids Dream of Electric Sheep?", Madison, The University of Wisconsin Press, págs. 53-65.

Dick, Philip K. (2003 [1968]), Do Androids Dream of Electric Sheep, London/Gollancz, SF Masterworks.

FrentZ, Thomas S. y Janice Hocker Rushing (1994), «The Frankenstein Myth in Contemporary Cinema», en W. L. Nothsine, C. Blair y G. A. Copeland (eds.), Critical Questions: Inventions, Creativity, and the Criticism of Discourse and Media, New York, St Martin's, págs. 155-182. Friedman, Lester D. y Allison B. Kavey (2016), Monstrous Progeny: A History of the Frankenstein Narratives, New Brunswick, Rutgers UP.

Galvan, Jill (1997), «Entering the Posthuman Collective in Philip K. Dick's Do Androids Dream of Electric Sheep?», Science Fiction Studies, 24/3, págs. 413-429.

Genette, Gérard (1982), Palimpsestes. La littérature au second degré, Paris, Seuil.

Graham, Elaine L. (2003), Representations of the Post/Human, New Brunswick, Rutgers UP.

Hoeveler, Diane Long (2016), «Nineteenth-Century Adaptations of Frankenstein», en A. Smith (ed.), The Cambridge Companion to Frankenstein, Cambridge, Cambridge University Press, págs. 175-189. JANCOVICH, Mark (2016), «Frankenstein and Film», en A. Smith (ed.), The Cambridge Companion to Frankenstein, Cambridge, Cambridge University Press, págs. 190-204.

Kerman, Judith B. (ed.) (1997), Retrofitting Blade Runner. Issues in Ridley Scott's "Blade Runner" and Philip K. Dick's "Do Androids Dream of Electric Sheep?", Madison, The University of Wisconsin Press.

KÖHLER, Erich (1990 [1970]), La Aventura caballeresca: ideal y realidad en la narrativa cortés, Barcelona, Sirmio.

KolB, William (1997), «Script to Screen: Blade Runner in Perspective», en J. B. Kerman (ed.), Retrofitting Blade Runner. Issues in Ridley Scott's "Blade Runner" and Philip K. Dick's "Do Androids Dream of Electric Sheep?", Madison, The University of Wisconsin Press, págs. 132-153.

Lavalley, Albert J. (1979), «The Stage and Film Children of Frankenstein: A Survey», en G. Levine y U. C. Knoepflmacher (eds.), The Endurance of Frankenstein: Essays on Mary Shelley's Novel, Berkeley, University of California Press, págs. 243-280.

Martín, Sara (2021), «Retrospective Posthumanism: Frankenstein According to Our New Vocabulary», Hélice, 30 (en prensa).

Mousley, Andy (2016), «The Posthuman», en A. Smith (ed.), The Cambridge Companion to Frankenstein, Cambridge, Cambridge University Press, págs. 158-172.

PARDO, Pedro Javier (2005), «Beyond Adaptation: Frankenstein's Postmodern Progeny», en M. Aragay (ed.), Books in Motion: 
Adaptation, Intertextuality, Authorship, Amsterdam, Rodopi, págs. 22342.

Pardo, Pedro Javier (2008), «From Blade Runner to Solaris: Covert Adaptations of Mary Shelley's Frankenstein in Contemporary Cinema», en F. García Bermejo (ed.), Multidisciplinary Studies in Language and Literature: English, American and Canadian, Salamanca, Ediciones Universidad de Salamanca, págs. 247-57.

PARDO, Pedro Javier (2018), «De la transescritura a la transmedialidad: poética de la ficción transmedial», en A. Gil González y P. J. Pardo (eds.), Adaptación 2.0. Estudios comparados sobre intermedialidad, Binges, Éditions Orbis Tertius, págs. 41-92.

PICART, Caroline Joan S. (2003), Remaking the Frankenstein Myth on Film: Between Laughter and Horror, Albany, State University of New York Press.

Pulido, Genara (2017), El Frankenstein de Mary Shelley y su descendencia literaria, Vigo, Academia del Hispanismo.

Punter, David (2016), «Literature», en A. Smith (ed.), The Cambridge Companion to Frankenstein, Cambridge, Cambridge University Press, págs. 205-218.

Roden, David (2018), «Speculative Posthumanism», en R. Braidotti y M. Hlavajova (eds.), Posthuman Glossary, London, Bloomsbury Academic.

SAINT-GelaIs, Richard (2011), Fictions transfuges. La transfictionnalité et ses enjeux, Paris, Seuil.

SCHOR, Esther (2003), «Frankenstein and Film», en E. Schor (ed.), The Cambridge Companion to Mary Shelley, Cambridge, Cambridge University Press, págs. 63-83.

SCHOR, Esther (ed.) (2003), The Cambridge Companion to Mary Shelley, Cambridge, Cambridge University Press.

Sebastián Martín, Miguel (2018), «All the Park's a Stage: Westworld as the Metafictional Frankenstein», ES Review. Spanish Journal of English Studies, 39, págs. 52-67.

Smith, Andrew (ed.) (2016), The Cambridge Companion to Frankenstein, Cambridge, Cambridge University Press.

Stevens, John (1973), Medieval Romance: Themes and Approaches, London, Hutchinson.

Suvin, Dark (1979), Metamorphoses of Science Ficition: On the Poetics and History of a Literary Genre, New Haven, Yale University Press.

TropP, Martin (1999), «Re-creating the Monster: Frankenstein and Film», en B. Tepa Lupack (ed.), Nineteenth-Century Women at the Movies: Adapting Classic Women's Fiction to Film, Bowling Green, Bowling Green State University Popular Press, págs. 23-77. 